\title{
Fluctuations in glucose availability prevent global proteome changes and physiological transition during prolonged chemostat cultivations of $\mathrm{S}$. cerevisiae
}

Wright, Naia Risager; Wulff, Tune; Palmqvist, Eva Akke; Jørgensen, Thomas Rubæk; Workman, Christopher T.; Sonnenschein, Nikolaus; Rønnest, Nanna Petersen; Herrgård, Markus J.

\section{Published in:}

Biotechnology and Bioengineering

Link to article, DOI:

10.1002/bit.27353

Publication date:

2020

Document Version

Peer reviewed version

Link back to DTU Orbit

Citation (APA):

Wright, N. R., Wulff, T., Palmqvist, E. A., Jørgensen, T. R., Workman, C. T., Sonnenschein, N., Rønnest, N. P., \& Herrgård, M. J. (2020). Fluctuations in glucose availability prevent global proteome changes and physiological transition during prolonged chemostat cultivations of S. cerevisiae. Biotechnology and Bioengineering, 117(7), 2074-2088. https://doi.org/10.1002/bit.27353

\section{General rights}

Copyright and moral rights for the publications made accessible in the public portal are retained by the authors and/or other copyright owners and it is a condition of accessing publications that users recognise and abide by the legal requirements associated with these rights.

- Users may download and print one copy of any publication from the public portal for the purpose of private study or research.

- You may not further distribute the material or use it for any profit-making activity or commercial gain

- You may freely distribute the URL identifying the publication in the public portal 
Naia Wright ORCID iD: 0000-0002-5299-6888

\title{
Fluctuations in glucose availability prevent global proteome changes and physiological transition during prolonged chemostat cultivations of $S$. cerevisiae
}

Naia Risager Wright ${ }^{1,2,4, *}$, Tune Wulff ${ }^{2}$, Eva Akke Palmqvist ${ }^{3}$, Thomas Rubæk Jørgensen ${ }^{2}$, Christopher T. Workman ${ }^{4}$, Nikolaus Sonnenschein ${ }^{2,4}$, Nanna Petersen Rønnest ${ }^{1}$, Markus J. Herrgård ${ }^{2,5}$

${ }^{1}$ Novo Nordisk A/S, Novo Alle 1, 2880 Bagsværd, Denmark

${ }^{2}$ The Novo Nordisk Foundation Center for Biosustainability, Technical University of Denmark, Building 220, Kemitorvet, 2800 Kgs. Lyngby, Denmark

${ }^{3}$ Follicum AB, Lund, Sweden

${ }^{4}$ Department of Biotechnology and Biomedicine, Technical University of Denmark, Building 223, Søltofts Plads, 2800 Kgs. Lyngby, Denmark

${ }^{5}$ Biolnnovation Institute, Ole Maaløes vej 3, 2200 København N, Denmark

*Correspondence: Naia Risager Wright, Novo Nordisk A/S, Email: nrsw@novonordisk.com

\begin{abstract}
Chemostat cultivation mode imposes selective pressure on cells, which may result in slow adaptation in the physiological state over time. We applied a two-compartment scale-down chemostat system imposing feast-famine conditions to characterize the long-term (100's of hours) response of $S$. cerevisiae to fluctuating glucose availability. A wild-type strain and a recombinant strain, expressing an insulin precursor, were cultured in the scale-down system, and analyzed at the physiological and proteomic level. Phenotypes of both strains This article has been accepted for publication and undergone full peer review but has not been through the copyediting, typesetting, pagination and proofreading process, which may lead to differences between this version and the Version of Record. Please cite this article as doi: 10.1002/bit.27353.
\end{abstract}

This article is protected by copyright. All rights reserved. 
were compared to those observed in a well-mixed chemostat. Our results show that $S$. cerevisiae subjected to long term chemostat conditions undergoes a global reproducible shift in its cellular state and that this transition occurs faster and is larger in magnitude for the recombinant strain including a significant decrease in the expression of the insulin product. We find that the transition can be completely avoided in the presence of fluctuations in glucose availability as the strains subjected to feast-famine conditions under otherwise constant culture conditions exhibited constant levels of the measured proteome for over 250 hours. We hypothesize possible mechanisms responsible for the observed phenotypes and suggest experiments that could be used to test these mechanisms.

Keywords

S. cerevisiae, scale-down, proteome, heterologous protein, feast-famine conditions

\section{Introduction}

Bakers’ yeast Saccharomyces cerevisiae, is a popular model organism and many functional genomics and molecular biology tools are available for engineering of this important species. This combined with the GRAS status assigned by the FDA, makes $S$. cerevisiae an attractive host for industrial production and S. cerevisiae is today used for production of various products in the biotech industry including biopharmaceuticals (Chen, Daviet, Schalk, Siewers, \& Nielsen, 2013).

Continuous and fed-batch cultivation mode are desirable cultivation strategies for industrial production processes as high cell densities can be reached and by-product formation avoided. In chemostat cultivations, cells are maintained in a steady-state growth environment by the supply of a constant medium flow with one or more final-cell-densitylimiting nutrients, and simultaneous removal of cultivation broth at a defined growth rate. Though, the commercial use of chemostat processes are limited, high yields of continuous 
recombinant protein production have been reported in the scientific literature (Peebo \& Neubauer, 2018). Chemostat cultivations are also widely applied as a tool for functional genomics research and characterization of microbial physiology in a controlled and reproducible manner (Hoskisson \& Hobbs, 2005; Jansen et al., 2005; Peebo \& Neubauer, 2018). However, steady-state chemostats exert a selective pressure on the cells, which may result in genetic or non-genetic adaptation or transition in the cellular state over time (Jansen et al., 2005; Mashego, Jansen, Vinke, Van Gulik, \& Heijnen, 2005; Seresht et al., 2013). Such metabolic and genetic changes over time are undesirable when chemostats are used for physiological characterization of microorganisms as the main purpose of using chemostats is to avoid changes in the cellular behavior. Stability and reproducibility of production strain phenotype is also important when chemostat mode is used for industrial production of e.g. pharmaceuticals.

The scale-up of industrial cultivation processes from laboratory scale with ideal mixing to production scale with heterogeneities in the fluid phase has been widely studied. Various laboratory scale-down systems have been designed for prediction of process performance in conditions where the host organisms are exposed to concentration gradients. These systems include setups of two coupled stirred tank reactors, a stirred tank reactor coupled to a plug flow reactor, or even three reactors coupled together (Olughu, Deepika, Hewitt, \& Rielly, 2018). The general idea behind the scale-down systems is to maintain different environmental conditions between the reactors, such as differences in oxygen level, substrate concentration or $\mathrm{pH}$. The cell culture is then transferred back and forth between the reactors mimicking the circulation of culture broth in a large scale-reactor (Heins \& Weuster-Botz, 2018; Limberg et al., 2017).

This article is protected by copyright. All rights reserved. 
We have previously demonstrated how the cultivation of a recombinant $S$. cerevisiae strain in a two-compartment scale-down reactor system operated in chemostat mode resulted in an increased production of a heterologous protein compared to the same strain cultivated in a well-mixed single compartment chemostat (Wright, Rønnest, \& Thykaer, 2016). In this current study, we used a similar approach to characterize the long-term responses of both a wild-type and an industrially relevant recombinant $S$. cerevisiae strain earlier examined by Seresht et al. (2013) to fluctuating and constant glucose levels on the proteomic and physiological level.

Cells cultivated in the chemostat system exhibited a physiological transition over a time scale of 100 's of hours resulting in significant changes in the relative composition of the cellular proteome. In contrast, the heterogeneous environment of the two-compartment system not only improved productivity of the recombinant insulin product but also suppressed changes in cell proteome for both the wild-type and the recombinant strain. These results demonstrate that fluctuations in glucose availability (feast-famine conditions) can be beneficial not only for heterologous protein production, but also in general for host cell stability of S. cerevisiae during prolonged continuous cultivation.

\section{Material and Methods}

\subsection{Yeast strain}

S. cerevisiae C.U17 (Seresht et al., 2013) was used as recombinant strain. This strain contains a 2- $\mu \mathrm{m}$ vector with an expression cassette encoding the TPI1 (Triose Phosphate Isomerase 1) promoter and a gene encoding a single-chain insulin precursor. Both HIS3 and URA3 are used as auxotrophic selection markers. The prototrophic strain CEN.PK1137D, was used as the wild-type reference.

This article is protected by copyright. All rights reserved. 


\subsection{Inoculum}

Cells were cultured over night in $300 \mathrm{~mL}$ shake flasks with $100 \mathrm{~mL}$ defined minimal growth medium (Seresht et al., 2013). The bioreactors were inoculated to an initial $\mathrm{OD}_{600}$ of 0.5 .

\subsection{Culture conditions}

Continuous chemostat cultivation of both strains was carried out in both a regular singlecompartment system and a two-compartment system in which the cells are exposed to feast-famine conditions. All the cultivations were initiated with a batch and a fed-batch phase in order to subculture the biomass. The temperature was $28^{\circ} \mathrm{C}, \mathrm{pH} 5.9$, aeration was $2 \mathrm{vvm}$ and dilution rate $0.1 \mathrm{~h}^{-1}$. A minimal medium with a glucose concentration of 75 $\mathrm{g} / \mathrm{L}$ (Seresht et al., 2013) was used in all cultivations. The single-compartment system was $0.5 \mathrm{~L}$ and $2 \mathrm{~L}$ fully instrumented and automatically controlled BIOSTAT $^{\circledR}$ reactors (Sartorius Stedim Biotech S.A, Germany). The two-compartment system has previously been described in Wright et al. (2016) (Figure 1). It consisted of two interconnected $0.5 \mathrm{~L}$ Sartorius stirred tank reactors between which the cultivation broth was circulated with a rate of $170 \mathrm{ml} / \mathrm{min}$ corresponding to a mixing time in the system of 30 seconds measured according to Poulsen \& Iversen (1997). The working volumes of the two reactors were kept constant at $170 \mathrm{~mL}$ (Tank 1) and $350 \mathrm{~mL}$ (Tank 2), respectively, during the continuous phase of a culture. This corresponds to an average residence time in Tank 1 of 1 minute and an average residence time in Tank 2 of 2 minutes. The working volume in Tank 2 was weight-controlled and cultivation broth was pumped from this tank in order to keep a constant volume in the system. The inlet probe transporting liquid from Tank 1 to Tank 2 was placed in the surface of the cultivation broth in order to keep a constant volume in Tank 1. Differences in glucose availability were simulated by directing all medium feed to 
Tank 1 (Figure 1), meaning that the cells experienced feast conditions in Tank 1 and famine condition in Tank 2. Both reactors in the two-compartment system were fully aerated with an aeration rate of $2 \mathrm{vvm}$ and a stirrer speed of $1000 \mathrm{rpm} . \mathrm{pH}$ was adjusted in both reactors. Five biological replicates in the single-compartment system and three biological replicates in the two-compartment system were performed for the recombinant strain whereas three biological replicates in both systems were carried out with the wild-type strain.

\subsection{Analysis}

\subsubsection{Samples}

Daily samples were taken for measurements of cell dry weight, extracellular insulin concentration, contamination and off-line $\mathrm{pH}$ control. In the two-compartment system, insulin concentration and cell dry weight were only measured from Tank 2 since previous data showed no difference in these measurements between compartments (Wright et al., 2016). Every second day during the continuous phase of the cultivations, samples were taken for determination of residual glucose concentration, extracellular metabolite concentration and intracellular proteins. These samples were taken from both of the reactors in the two-compartment system.

\subsubsection{Cell Dry Weight, extracellular glucose, ethanol, acetate and glycerol} Measurements of cell dry weight, extracellular glucose, ethanol, acetate and glycerol were performed as described in Wright et al. (2016). The detection limit for ethanol, acetate and glycerol were $1 \mathrm{~g} / \mathrm{L}, 0.01 \mathrm{~g} / \mathrm{L}$ and $0.01 \mathrm{~g} / \mathrm{L}$ respectively.

\subsubsection{Off-gas}

The off-gas from all cultures was measured at-line with a Prima $\delta \mathrm{B}$ mass spectrometer. For cultivations in the two-compartment system off-gas was measured from both reactors.

This article is protected by copyright. All rights reserved. 


\subsubsection{Analysis of Recombinant Insulin}

The supernatant from the cell dry weight measurements was diluted 1:1 with acetic acid and the insulin concentration in the supernatant was measured by HPLC analysis using a Waters ACQUITY BEH 2.1x50mm column (C18,1.7 $\mu \mathrm{m})$.

\subsubsection{Analysis of Intracellular Proteins}

Proteomics samples from minimum 3 biological replicates were analyzed for each cultivation condition. For each cultivation minimum 6 samples were analyzed distributed throughout the entire continuous cultivation period. In the two-compartment system samples were taken from both reactor 1 and reactor 2 meaning that minimum 12 samples were analyzed for each of the cultivations in the two-compartment system (See supplementary materials Table S2,S3 for an overview of the different samples).

Preparation of protein extract from S. cerevisiae was done as previously described in Bonde et al. (2016). Liquid chromatography was performed on a Cap-LC system (Thermo scientific) coupled to an $75 \mu \mathrm{m}$ x $15 \mathrm{~cm} 2 \mu \mathrm{m}$ C18 easy spray column (Thermo Scientific). The flow rate was set to $1.2 \mathrm{ul}$ and using a stepped gradient, going from $4 \%$ to $40 \%$ acetonitrile in water over 50 minutes, the samples were sprayed into an Orbitrap Q Exactive HF-X mass spectrometer (Thermo Scientific). MS-level scans were performed with Orbitrap resolution set to 60,000; AGC Target 1.0e6; maximum injection time 50 ms; intensity threshold 5.0e3; dynamic exclusion 25 sec. Data dependent MS2 selection was performed in Top 12 mode with HCD collision energy set to 28\% (AGC target 1.0e4, maximum injection time $22 \mathrm{~ms}$ ). The resulting data were analyzed using Proteome Discover 2.3 (Thermo Fisher Scientific, Massachusetts, US) with the following settings: Fixed modifications: Carbamidomethyl (C). Varible modifications: oxidation of methionine residues. First search mass tolerance $20 \mathrm{ppm}$ and a MS/MS tolerance of $20 \mathrm{ppm}$. Trypsin 
was selected as enzyme and allowing one missed cleavage. FDR was set at $0.1 \%$. Data was searched against the $S$. cerevisiae database retrieved from Uniprot with proteome ID AUP000002311. The sequence of the heterologous insulin was added to the proteome database. The proteins were quantified by label-free quantification and the abundance of each protein is reported as the relative intensity with respect to total intensity of all identified peptides. The datasets can be found on data.dtu.dk (DOI: 10.11583/DTU.9833936). Moreover, the mass spectrometry proteomics data have been deposited to the ProteomeXchange Consortium (http://proteomecentral.proteomexchange.org) via the PRIDE partner repository (Vizcaíno et al., 2013) with the dataset identifier PXD015536.

\subsection{Data processing of proteome data}

For the further processing and data analysis of the proteome dataset, only proteins with measurements in all samples were applied. This means that a dataset of 2771 proteins for the cultivations with the recombinant strain and a dataset of 2861 proteins for the cultivations with the wild-type strain was used.

\subsubsection{Hierarchical clustering}

The proteome data used for hierarchical clustering were scaled using Proteome Discover 2.3 (Thermo Fisher Scientific, Massachusetts, US) so the average across all samples for a particular protein is 100 . The data were further standardized by subtracting the mean and dividing by the standard deviation. Hierarchical clustering of proteome data was performed using the Ward method with Euclidian distance as distance measure by means of the scipy.cluster.hierarchy package in Python (Oliphant, 2007).

This article is protected by copyright. All rights reserved. 


\subsubsection{Gene ontology term selection and annotation}

Gene ontology (GO) process terms were taken from the 2017-01-14 GO slim Mapping list downloaded from SGD Project (2019, July 17). A one-sided Fisher's exact test was used to investigate whether the different clusters, originating from the hierarchical clustering, were enriched with proteins annotated with certain GO process terms. The test was performed using the R package bc3net package (Simoes, Tripathi, \& Emmert-Streib, 2012).

\section{Proteome changes over time}

Two different approaches, showing similar results, were applied in order to determine whether proteins were increasing, decreasing or stable over time: 1) A robust linear regression model to determine whether proteins were significantly changing with time using the R package MASS (Venables \& Ripley, 2002). For significantly changing proteins the slope of the model was used to determine whether the protein was decreasing or increasing with time. Benjamin/Hochberg analysis was used to correct the p-values. 2) Early cultivation state was defined as continuous cultivation times before 100 hours of continuous cultivation ( $\sim 14$ generations in continuous phase) and late cultivation state as continuous cultivation times after 200 hours of continuous cultivation ( 29 generations in continuous phase). The level of a given protein in a given cultivation state was calculated as the mean of the protein abundances of all samples from all biological replicates in the particular state. A two-sided t-test was applied, using the scipy.stats package in Python (Oliphant, 2007). The P-values from the two-sided t-test was corrected with false discovery rate using Benjamini/Hochberg.

\subsubsection{Transcription factor analysis}

A one-sided Fisher's exact test was used to investigate whether the different clusters, originating from the hierarchical clustering, were enriched with proteins regulated by specific transcription factors. The transcription factor network list was taken from the 
curated regulatory network available at Yeastract (Teixeira et al., 2018). The test was performed using the R package bc3net (Simoes et al., 2012).

\section{Results}

In this study, prolonged continuous cultivations of a wild-type $S$. cerevisiae strain and a recombinant $S$. cerevisiae strain producing extracellularly secreted insulin were investigated. The cultivations were carried out in both a single-compartment setup with ideal mixing and a scale-down two-compartment system imposing feast-famine conditions in order to mimic large-scale production conditions.

\subsection{Cellular physiology}

The residual glucose concentration for all cultivations were close to zero indicting carbonlimited growth (Supplementary materials, Figure S1). In the two-compartment system the average residual glucose concentration in Tank 1 is around $4 \mathrm{mg} / \mathrm{L}$ higher than the concentration in Tank 2 (Table 1). The glucose uptake rate in the single-compartment system was calculated to be $\sim 1.4 \mathrm{mmol} / \mathrm{gDW} / \mathrm{h}$ for both strains. In Tank 1 of the twocompartment system the glucose uptake rate was $\sim 4.2 \mathrm{mmol} / \mathrm{gDW} / \mathrm{h}$ whereas almost no glucose was consumed in Tank 2. This confirms that the cells experienced feast conditions in Tank 1 and famine conditions in Tank 2.

The insulin concentration in the beginning of continuous phase is higher in the twocompartment system compared to the single-compartment system (Figure 2A). In the twocompartment system, the insulin concentration was stable throughout the entire cultivation period whereas the insulin concentration in the single-compartment setup decreased to almost half of the maximum value within 200 hours of continuous cultivation (Figure 2A). A slightly different mean biomass yield between the two reactor setups were observed for both strains (two-sided t-test, p-value $<0.05$ ) (Figure 2B, data from Wild-type strain in 
Supplementary material, Figure S2, for mean values and p-values see supplementary material, Table S1).

No extracellular metabolites above the detection level were measured for the wild-type strain in either reactor setup. For the recombinant strain, only acetate production was detected (Figure 2C). Calculation of carbon balances accounted for more than $93 \%$ of measured and estimated carbon compounds in all cultivations (data not shown).

The levels of $\mathrm{CO}_{2}$ production (CER), $\mathrm{O}_{2}$ consumption (OUR) and dissolved oxygen tension were similar between biological replicates (Supplementary materials, Figure S3 Figure S11). In the two-compartment system CER, OUR and dissolved oxygen tension were stable throughout the entire cultivation period for both the recombinant strain and the wild-type strain (Figure 3B,D). Oscillations were observed in CER, OUR and dissolved oxygen concentration for both strains cultivated in the single-compartment system. For the recombinant strain the oscillations stopped after around 100 hours of continuous cultivation, where an increase in the average level of CER and OUR was observed (Figure 3A). The oscillations in the wild-type strain continued until around 180 hours of continuous cultivation, where a small increase in CER and OUR were also observed for two of the biological replicates (Supplementary materials, Figure 9 - Figure 10). The oscillations had a period of approximately 3 hours in all replicates.

\subsection{Dynamics of intracellular proteins}

Intracellular protein levels measured in the two-compartment system were generally observed to be constant throughout the entire cultivation period for both strains. Only 8 proteins were found to be significantly changing in the wild-type strain in either compartment while only 1 protein was observed to change in the recombinant strain (robust linear regression model, q-value $<0.05$ ). This was not the case for cultivations in 
the single-compartment system where many of the measured proteins changed over time (66 \% for the recombinant strain ranging from [-0.023;0.021] log2FC/h and $25 \%$ for the wild-type strain ranging from [-0.020;0.009] log2FC/h; robust linear regression model, qvalue $<0.05)$. No significant differences in the protein abundances between the two reactors in the two-compartment systems were observed (Supplementary materials, Figure S15, S16). This is in line with the expectation since the turnover rates of intracellular proteins in S. cerevisiae are within hours whereas the residence time in the two reactors of the two-compartment system is on average 1 and 2 minutes respectively (Figure 1) (Christiano, Nagaraj, Fröhlich, \& Walther, 2014).

A principal component analysis (PCA) of samples taken from the single-compartment system indicated that the samples could be separated into two main clusters depending on when in the cultivation period the samples were taken (Figure 4A,C). No time-dependent pattern could be found for the cultures in the two-compartment system (Figure 4B,D). It should be noticed that the PCA plots in Figure 4 cover less than $50 \%$ of the variance in the data. However, the clustering of the samples according to cultivation time was confirmed by the trends of several intracellular proteins over time, for instance the glycolytic proteins Fructose-1,6-Bisphosphate aldolase (Fba1p), Glucokinase (Glk1p), and Triose-phosphate isomerase (Tpi1p) (Figure 5).

\subsection{Proteome changes in single-compartment system}

Hierarchical clustering of the proteome data from the cultivations in the singlecompartment system indicated that groups of proteins had distinct patterns of timedependent behavior in both the recombinant strain and the wild-type strain (Figure 6). By visual inspection it was observed that, the protein levels for the recombinant strain were either decreasing after 100 hours in continuous phase (Cluster 1, Figure 6), increasing after 100 hours in continuous phase (Cluster 3 and Cluster 4, Figure 6A) or relatively stable 
throughout the entire cultivation period (other clusters in Figure 6A). Fisher's exact test applied to the groups of proteins decreasing over time (Figure 6A, Cluster 1) and the proteins increasing over time (Figure 6A, Cluster 3 and Cluster 4) showed that the clusters were enriched with proteins annotated with certain GO slim process terms (q-value $<0.05$ ) (Table 2). The downregulated proteins had an overrepresentation of proteins associated with cellular metabolism whereas the clusters containing proteins upregulated over time had an overrepresentation of GO terms related to the protein synthesis machinery (Table 2). For the wild-type strain cultivated in the single-compartment system a cluster of proteins increasing after 180 hours and a cluster of proteins decreasing after 180 hours were found (Figure 6B). The clusters with decreasing and increasing proteins were enriched with proteins from many of the same GO process terms that were found for the recombinant strain (Table 2).

In addition to the analysis of the GO slim term enrichment in the up- or downregulated protein clusters, we also sought to identify possible transcription factors (TF) responsible for controlling these changes using transcriptional networks extracted from Yeastract database (Teixeira et al., 2018). The outcome of Fischer's exact test analysis of TFregulated protein sets for the recombinant strain is shown in Table 3. Moreover, it is indicated if the transcription factors were also found to regulate similar clusters from the clustering of the wild-type strain. It should be noted that only half of these transcription factors have themselves been identified in the proteomics dataset.

Even though the downregulated protein clusters had overrepresentation of proteins in specific GO slim categories, all of these categories also contained proteins that were upregulated over time (Supplementary materials, Figure S26).

This article is protected by copyright. All rights reserved. 


\section{Discussion}

4.1 Physiology of S. cerevisiae exposed to heterogeneous and homogeneous conditions during prolonged continuous cultivations

In this study we compared the behavior of two $S$. cerevisiae strains during prolonged cultivation in a well-mixed single-compartment system and a two-compartment system imposing feast-famine conditions. The single-compartment system was operated as a chemostat with a dilution rate of $0.1 \mathrm{~h}^{-1}$. No overflow metabolism was observed for any of the strains meaning that the cultivations were operated below the critical dilution rate resulting in a purely oxidative metabolism. The two-compartment system was also operated with an overall dilution rate of $0.1 \mathrm{~h}^{-1}$. In Tank 1 of the two-compartment system the glucose uptake rate was above the critical glucose uptake rate at which ethanol is produced (Table 1; Supplementary materials, Figure S12). Moreover, the biomass yield in the two-compartment system was lower than the yield observed in the single-compartment system (Figure 2B; Supplementary materials, Table S1). This suggests that the cells exhibit respiro-fermentative metabolism in the two-compartment system. Since no ethanol formation could be detected in the two-compartment system we speculate that the ethanol produced in Tank 1 of the two-compartment system is metabolized in Tank 2 resulting in an ethanol concentration in the system which will never exceed the detection limit for the analysis $(1 \mathrm{~g} / \mathrm{L})$.

In the single-compartment system oscillations in OUR and CER were observed for both strains (Figure 3). The oscillations stopped at the time point where the most significant changes of the proteome occurred i.e. after 100 hours of continuous cultivation with the recombinant strain and after 180 hours of cultivation with the wild-type strain. Synchronous oscillations in CER and OUR have previously been reported for chemostat cultivations and are referred to as the yeast metabolic cycle (YMC) (Burnetti, Aydin, \& 
Buchler, 2015). The population synchrony of YMC is thought to arise from YMC-to-YMC coupling across cells via secreted metabolites. The loss of population synchrony that we observe might arise due to the single cells no longer having an YMC oscillator or because the YMC oscillators in cells have lost their ability to entrain other YMC oscillators (Burnetti et al., 2015). This loss might be a result of the observed changes in the relative composition of the cellular proteome. Synchronous oscillations have also previously been reported in batch cultures upon diauxic shift to pure respiration on ethanol (Mochan \& Pye, 1973) and the oscillations may be a sign that metabolism is transitioning to a new state. We speculate that the absence of synchronous oscillations in the two-compartment system could be explained by the constant shifting between respiratory and fermentative metabolism.

Similar to insulin production, acetate production in cultures with the recombinant strain, was stable in the two-compartment system whereas it decreased over time in the singlecompartment system, indicating metabolic adaptation (Figure 2C). The acetate formation was not observed for the wild-type strain and may indicate an increased need for NADPH in the recombinant strain due to the insulin production. The acetate pathway in $S$. cerevisiae can produce NADPH when excess NADPH is required and increased NADPH supply has been shown to be beneficial for recombinant protein production in Chinese Hamster Ovary (CHO) and Pichia pastoris (Grabowska \& Chelstowska, 2003; Huang, Bao, Hallström, Petranovic, \& Nielsen, 2017). The decrease in acetate production over time in the single-compartment system might be explained by the decrease in insulin production and thereby a decreased need for NADPH.

Control cultivations in the two-compartment system with feed in both reactors showed similar behavior as cultivations in the single-compartment system (Supplementary 
material, Figure S13, S14). These results confirm that the overall observed differences in cellular physiology between cultures in the two setups were caused by the imposed feastfamine conditions and not by the two-compartment setup itself.

4.2 Changes in composition of cellular proteome under prolonged aerobic glucose limited conditions

Transcriptome and metabolome changes occurring over time in continuous culture of both the wild-type strain and the recombinant strain in a single-compartment system have been described in a previous study (Seresht et al., 2013). In the current study, we investigated the changes at the protein level confirming that changes in the cellular proteome occur for both recombinant and wild-type strains, and that the changes are larger and take place faster for the recombinant strain (Figure 6). Over all, our proteomics data mirrors the changes observed at the transcriptomic and metabolomics levels in the previous study.

Most of the measured proteins which were significantly changing over time, were increasing in expression with cultivation time (Supplementary materials, Figure S26). This includes proteins related to the protein synthesis machinery. An upregulation of genes related to the ribosomal biogenesis has previously been reported for S. cerevisiae strains evolved during long term chemostat cultivations (Wenger et al., 2011). A decrease over time in many of the proteins involved in the central carbon metabolism, including most of the glycolytic enzymes, enzymes in the CTA cycle and the pentose phosphate pathway are in line with previous observations of $S$. cerevisiae subjected to prolonged chemostat cultivation (Jansen et al., 2005; Mashego et al., 2005; Seresht et al., 2013) (See Supplementary materials, Figure S19-S26 for patterns of the individual enzymes).

The high-affinity glucose transporters (HXT2 and HXT6) were increasing overtime in both strains cultivated in the single-compartment system to levels that were higher than the constant levels observed in the two-compartment system (Supplementary materials, Figure

This article is protected by copyright. All rights reserved. 
S19-S22). This is in agreement with the affinity of the transporters and previous observations (Buziol et al., 2008; Mashego et al., 2005). The intermediate-affinity glucose transporter HXT5 was decreasing with $0.022 \log 2 \mathrm{FC} / \mathrm{h}$ for the recombinant strain and 0.01 $\log 2 \mathrm{FC} / \mathrm{h}$ for the wild-type strain in the single-compartment system.

In the study by Seresht et al. (2013) moderate decreases in the metabolite levels of amino acids were observed for the wild-type strain whereas a transcriptional upregulation of the de novo amino acid biosynthesis for the recombinant strain was reported. In this study we saw an enrichment of proteins related to the GO slim process term Cellular amino acid metabolic process in the cluster of proteins decreasing over time for the recombinant strain cultivated in the single-compartment system (Table 2). However, both significant increases and decreases in levels of proteins related to the GO slim term were observed over time (Supplementary materials, Figure S26). Overall no clear trend between upregulated and downregulated proteins in the GO term Cellular amino acid metabolic process could be found and the changes were not specific to certain amino acid pathways.

The protein encoded by the auxotrophic marker URA3 (Ura3p) increased significantly over time in the recombinant strain cultivated in the single-compartment system $(0.8 \log 2$ fold change) together with several other proteins involved in the de novo synthetic pathway of uracil (two sided t-test, q-value <0.05), (Supplementary material, Table S4). The results confirm previous observations at the transcriptional level (Seresht et al., 2013). These changes were not observed for the wild-type strain cultivated in the singlecompartment system (Supplementary material, Table S5) and suggest that some of the changes in the cellular proteome composition observed over time for the recombinant strain could be related to the applied auxotrophic markers. No significant changes in the 
protein encoded by the other auxotrophic marker HIS3 were observed (two sited t-test, qvalue <0.05), (Supplementary material, Table S6, S7).

Our results together with results from previous transcriptomic and metabolomic studies indicate that yeast subjected to long term continuous culture undergoes a reproducible transition in its cellular state (Seresht et al., 2013). The novel findings in this current study demonstrate that the transition can be completely avoided by the application of feastfamine conditions in both wild-type and recombinant strains. Yeast subjected to fluctuations in glucose availability under otherwise constant culture conditions exhibited more or less constant levels of the measured proteins for over 250 hours. These results indicate that feast-famine conditions present in large scale can be beneficial for prolonged continuous cultivations of $S$. cerevisiae with respect to heterologous protein production, and can result in constant relative composition of the cellular proteome over time. There are only a few other examples in literature where glucose fluctuations lead to positive effects. These include a higher 'dough raising activity’ of baker's yeast (George, Larsson, Olsson, \& Enfors, 1998), an increased sterol synthesis in S. cerevisiae (Marbà-Ardébol, Bockisch, Neubauer, \& Junne, 2018) and an increased viability in E. coli (Hewitt, NebeVon Caron, Axelsson, McFarlane, \& Nienow, 2000).

\subsection{What drives changes in heterologous insulin production?}

The decrease in insulin production over time in the single-compartment system coincide with the observed changes in the relative composition of the cellular proteome. At a constant dilution rate the fraction of the proteins of the total biomass of the cell is constant (Nilsson \& Nielsen, 2016). As many of the protein levels increase over time in the singlecompartment system, the decrease in insulin production may be a necessary result of this increase due to the overall finite proteome pool. Another reason for the reduced insulin expression could be a decrease in the activity of the TPI1 promoter. The activity of TPI1 
has previously been reported to decrease over time in a chemostat (Seresht et al., 2013) and in the present study a decrease in Tpi1p was observed (Figure 5C). In the twocompartment system, where insulin production was maintained at a higher constant level, the measured abundances of Tpi1p was constant over time. The Tpi1p level was also slightly higher than observed in the single-compartment system (Figure 5C). This indicates that downregulation of the TPI1 promoter activity contributes to the decline in the insulin production over time in the single-compartment system.

4.4 What drives the transition in the single-compartment system and why is this mechanism repressed by feast-famine conditions?

Previous research into yeast adaptation and physiology has identified several different mechanisms that may be involved in the observed physiological transition in the singlecompartment system. These include Energetic optimizations, Unfolded protein response (UPR) and Cell aging. In this section, we link these mechanisms to our results to formulate hypotheses for what drives the proteomic changes in the single-compartment system and why these mechanisms are repressed by fluctuations in glucose availability (Figure 7).

\subsubsection{Energetic optimization of metabolism}

Protein synthesis is an energetically expensive process. Cultivating the cells in a chemostat below the critical dilution rate could lead to a glycolytic overcapacity within the cells. Glucose-limited cultivation conditions might therefore prove a selective pressure on cells to economize on protein synthesis (Jansen et al., 2005). In the two-compartment setup, the cells experience very high glucose uptake rates pointing to a higher flux through glycolysis compared to the single-compartment system. This suggests that an economization perspective drives the proteomic changes in the single-compartment system but not in the two-compartment system, as the cells have no glycolytic overcapacity in this system.

This article is protected by copyright. All rights reserved. 


\subsubsection{Unfolded protein response (UPR) as a regulator of the cellular state}

Seresht et al. (2013) suggested that misfolded insulin accumulates in the endoplasmic reticulum (ER) in the recombinant strain during prolonged chemostat cultivation resulting in an UPR, facilitating the observed change in cellular state. In this study 37 proteins of the upregulated UPR genes reported by Seresht et al. (2013) were measured and 25 of these proteins were significantly increasing over time for the recombinant strain (two-sided ttest, q-value < 0.05) (Supplementary material, Table S8). In comparison, 13 of the proteins were also increasing over time for the wild-type strain indicating that the production of recombinant insulin results in an additional burden on the cells (Supplementary material, Table S9). In general, an increase of proteins related to the GO slim term protein folding were observed over time in both the recombinant and the wild-type strain (Supplementary materials, Figure S26). In the two-compartment system, no significant changes over time in the proteins related to protein folding and UPR response were observed (two-sided ttest, q-value $<0.05$ ). This indicates that the burden of the insulin product is not the main cause for the proteome changes since the production of insulin is actually higher in the two-compartment system.

\subsubsection{Cell aging mechanism}

We speculate that the prolonged cultivation of cells in the single-compartment system for more than 250 hours (> 36 generations) resulted in a cellular response similar to the cell aging mechanism.

One hallmark of the cell aging mechanism is mitochondrial dysfunction and ROS generation due to increased electron leakage. The purely oxidative metabolism in the single-compartment system is likely to result in formation of reactive oxygen species (ROS) (Temple, Perrone, \& Dawes, 2005). Moreover, the observed increase in CER and OUR (Figure 3) could be a sign of mitochondrial dysfunction, as an increased electron leak 
would result in a higher respiration to generate the necessary energy (Dejean et al., 2002). Another hallmark of the aging mechanism is increased stress responses (Janssens \& Veenhoff, 2016). In the single-compartment system several of the transcription factors regulating proteins in the downregulated clusters of both strains are related to stress (e.g. Yap1, Msn2p, Msn4p, Cts6p and Hsf1p; Table 3). Yap1p itself was increased during cultivation in the single-compartment system with the recombinant strain (Supplementary materials, Figure S25). Epigenetic alterations are also a sign of cell aging and in this study, we observed an increased level of several proteins related to the GO slim process term histone modifiers (Supplementary materials, Figure S26). Furthermore, the transcription factors Sir2p, Taf14p and Isw2p which are involved in chromatin modifications, were all found to significantly regulate proteins in the upregulated clusters of the recombinant strain (Table 3). Decreased glycolytic and increased gluconeogenetic activities have also been related to aging (Lin, Manchester, \& Gordon, 2001; Reverter-Branchat, Cabiscol, Tamarit, \& Ros, 2004). We observed a decrease in both glycolytic and gluconeogenetic enzymes over time for the two strains (Supplementary materials, Figure S17-S20).

Intermittent fasting and reduction of calorie intake in general has been shown to increase healthy lifespan, extend longevity and reduce oxidative stress in many organisms including S. cerevisiae (Fontana \& Partridge, 2015; Longo \& Mattson, 2014; Maslanka \& ZadragTecza, 2019). The cells experience the imposed fluctuations in glucose availability in our two-compartment system as intermittent fasting. The absence of changes in the cellular proteome related to cellular aging in the two-compartment system is thus in line with these results.

ROS formation and oxidative stress are linked to the production of heterologous proteins (Martínez, Meza, Petranovic, \& Nielsen, 2016). This indicates that the recombinant strain 
may generate ROS not only due to the nature of single-compartment system, but also due to the burden of the insulin product. This additional stress related to the insulin production could explain the amplified proteomic changes in the recombinant strain compared to the wild-type strain. However, the stress response was not observed in the two-compartment system where higher production of recombinant protein was observed. This suggests that the feast-famine conditions reduces oxidative stress generated due to the heterologous insulin production and as part of the potential cell aging mechanism.

Mutations have previously been found in strains evolved under long term chemostat conditions (Wenger et al., 2011). However, we find it unlikely that mutations can explain the phenomena observed in this study due to the highly reproducible time scales of the observed physiological and proteomic changes in replicate cultivations. It is also not clear how fluctuations in glucose availability in the two-compartment level would prevent mutations as the dilution rate and numbers of generations were the same between the systems.

To follow up on the hypothesis that the aging mechanism might be responsible for the observed phenotypes in the study, one could measure ROS generation and cell distribution in term of number of bud scars or cells size as function of cultivation time. The oxidative stress level in the cultures could also be increased by addition of e.g. hydrogen peroxide in order to see whether this accelerates or enhances the physiological and proteomic changes in the single-compartment system.

\section{Conclusions}

The results presented in this study show that feast-famine conditions in large scale production reactors can be beneficial for heterologous protein production by counterintuitively keeping the cell population in a constant physiological and proteomic 
state. We speculate that the stabilizing effect of feast-famine conditions observed for the two S. cerevisiae strains in the carbon limited chemostat may be transferable to other microorganisms and other continuous operation modes such as nitrogen or phosphate limited cultures. Moreover, the results suggest that scale-down systems should not only be applied for the purpose of production scale-up/scale-down, but could also be applied in functional genomic research and when host cell physiology are studied in order to avoid the effects of the artificial constant selection pressure in a chemostat.

\section{Acknowledgments}

The research leading to these results has received funding from the Innovation Fund Denmark, Denmark and the Novo Nordisk Foundation, Denmark.

\section{References}

Bonde, M. T., Pedersen, M., Klausen, M. S., Jensen, S. I., Wulff, T., Harrison, S., ... Sommer, M. O. A. (2016). Predictable tuning of protein expression in bacteria. Nature Methods. https://doi.org/10.1038/nmeth.3727

Burnetti, A. J., Aydin, M., \& Buchler, N. E. (2015). Cell cycle Start is coupled to entry into the yeast metabolic cycle across diverse strains and growth rates. Molecular Biology of the Cell. https://doi.org/10.1091/mbc.e15-07-0454

Buziol, S., Warth, L., Magario, I., Freund, A., Siemann-Herzberg, M., \& Reuss, M. (2008). Dynamic response of the expression of hxt1, hxt5 and hxt7 transport proteins in Saccharomyces cerevisiae to perturbations in the extracellular glucose concentration. Journal of Biotechnology. https://doi.org/10.1016/j.jbiotec.2008.02.002

Chen, Y., Daviet, L., Schalk, M., Siewers, V., \& Nielsen, J. (2013). Establishing a platform cell factory through engineering of yeast acetyl-CoA metabolism. Metabolic Engineering. https://doi.org/10.1016/j.ymben.2012.11.002

Christiano, R., Nagaraj, N., Fröhlich, F., \& Walther, T. C. (2014). Global Proteome Turnover Analyses of the Yeasts S.cerevisiae and S.pombe. Cell Reports. https://doi.org/10.1016/j.celrep.2014.10.065

Dejean, L., Bunoust, O., Schaeffer, J., Guérin, B., Rigoulet, M., \& Beauvoit, B. (2002). Control of growth yield of yeast on respiratory substrate by mitochondrial content. In Thermochimica Acta. https://doi.org/10.1016/S00406031(02)00244-7

Fontana, L., \& Partridge, L. (2015). Promoting health and longevity through diet: From model organisms to humans. Cell. https://doi.org/10.1016/j.cell.2015.02.020

George, S., Larsson, G., Olsson, K., \& Enfors, S. O. (1998). Comparison of the Baker's yeast process performance in laboratory and production scale. Bioprocess Engineering, 18(2), 135-142. https://doi.org/10.1007/s004490050423

Grabowska, D., \& Chelstowska, A. (2003). The ALD6 gene product is indispensable for providing NADPH in yeast cells lacking glucose-6-phosphate dehydrogenase activity. Journal of Biological Chemistry. https://doi.org/10.1074/jbc.M210076200

Heins, A. L., \& Weuster-Botz, D. (2018). Population heterogeneity in microbial bioprocesses: origin, analysis, mechanisms, and future perspectives. Bioprocess and Biosystems Engineering. https://doi.org/10.1007/s00449018-1922-3

This article is protected by copyright. All rights reserved. 
Hewitt, C. J., Nebe-Von Caron, G., Axelsson, B., McFarlane, C. M., \& Nienow, A. W. (2000). Studies related to the scale-up of high-cell-density E. coli fed-batch fermentations using multiparameter flow cytometry: effect of a changing microenvironment with respect to glucose and dissolved oxygen concentration. Biotechnol Bioeng, 70(4), 381-390. Retrieved from file:///N:/PhD/Artikler/Hewitt_et_al-2000-

Biotechnology_and_Bioengineering.pdf

Hoskisson, P. A., \& Hobbs, G. (2005). Continuous culture - Making a comeback? Microbiology. https://doi.org/10.1099/mic.0.27924-0

Huang, M., Bao, J., Hallström, B. M., Petranovic, D., \& Nielsen, J. (2017). Efficient protein production by yeast requires global tuning of metabolism. Nature Communications. https://doi.org/10.1038/s41467-017-00999-2

Jansen, M. L. A., Diderich, J. A., Mashego, M., Hassane, A., de Winde, J. H., Daran-Lapujade, P., \& Pronk, J. T. (2005). Prolonged selection in aerobic, glucose-limited chemostat cultures of Saccharomyces cerevisiae causes a partial loss of glycolytic capacity. Microbiology. https://doi.org/10.1099/mic.0.27577-0

Janssens, G., \& Veenhoff, L. (2016). Evidence for the hallmarks of human aging in replicatively aging yeast. Microbial Cell. https://doi.org/10.15698/mic2016.07.510

Limberg, M. H., Schulte, J., Aryani, T., Mahr, R., Baumgart, M., Bott, M., ... Oldiges, M. (2017). Metabolic profile of 1,5-diaminopentane producing Corynebacterium glutamicum under scale-down conditions: Blueprint for robustness to bioreactor inhomogeneities. Biotechnol Bioeng, 114(3), 560-575. https://doi.org/10.1002/bit.26184

Lin, S. S., Manchester, J. K., \& Gordon, J. I. (2001). Enhanced Gluconeogenesis and Increased Energy Storage as Hallmarks of Aging in Saccharomyces cerevisiae. Journal of Biological Chemistry. https://doi.org/10.1074/jbc.M103509200

Longo, V. D., \& Mattson, M. P. (2014). Cell Metabolism Review Fasting: Molecular Mechanisms and Clinical Applications. Cell Metabolism. https://doi.org/10.1016/j.cmet.2013.12.008

Marbà-Ardébol, A. M., Bockisch, A., Neubauer, P., \& Junne, S. (2018). Sterol synthesis and cell size distribution under oscillatory growth conditions in Saccharomyces cerevisiae scale-down cultivations. Yeast. https://doi.org/10.1002/yea.3281

Martínez, J. L., Meza, E., Petranovic, D., \& Nielsen, J. (2016). The impact of respiration and oxidative stress response on recombinant $\alpha$-amylase production by Saccharomyces cerevisiae. Metabolic Engineering Communications. https://doi.org/10.1016/j.meteno.2016.06.003

Mashego, M. R., Jansen, M. L. A., Vinke, J. L., Van Gulik, W. M., \& Heijnen, J. J. (2005). Changes in the metabolome of Saccharomyces cerevisiae associated with evolution in aerobic glucose-limited chemostats. FEMS Yeast Research. https://doi.org/10.1016/j.femsyr.2004.11.008

Maslanka, R., \& Zadrag-Tecza, R. (2019). Less is more or more is less: Implications of glucose metabolism in the regulation of the reproductive potential and total lifespan of the Saccharomyces cerevisiae yeast. Journal of Cellular Physiology. https://doi.org/10.1002/jcp.28386

Mochan, E., \& Pye, E. K. (1973). Respiratory oscillations in adapting yeast cultures. Nature New Biology. https://doi.org/10.1038/newbio242177a0

Nilsson, A., \& Nielsen, J. (2016). Metabolic Trade-offs in Yeast are Caused by F1F0-ATP synthase. Scientific Reports, 6. https://doi.org/10.1038/srep22264

Oliphant, T. E. (2007). SciPy: Open source scientific tools for Python. Comput. Sci. Eng. https://doi.org/10.1109/MCSE.2007.58

Olughu, W., Deepika, G., Hewitt, C., \& Rielly, C. (2018). Insight into the large-scale upstream fermentation environment using scaled-down models. Journal of Chemical Technology and Biotechnology. https://doi.org/10.1002/jctb.5804

Peebo, K., \& Neubauer, P. (2018). Application of Continuous Culture Methods to Recombinant Protein Production in Microorganisms. Microorganisms. https://doi.org/10.3390/microorganisms6030056

Poulsen, B. R., \& Iversen, J. J. L. (1997). Mixing determinations in reactor vessels using linear buffers. Chemical Engineering Science, 52(6), 979-984. https://doi.org/10.1016/S0009-2509(96)00466-6 
Reverter-Branchat, G., Cabiscol, E., Tamarit, J., \& Ros, J. (2004). Oxidative Damage to Specific Proteins in Replicative and Chronological-aged Saccharomyces cerevisiae. Journal of Biological Chemistry. https://doi.org/10.1074/jbc.m404849200

Seresht, A. K., Cruz, A. L., De Hulster, E., Hebly, M., Palmqvist, E. A., Van Gulik, W., ... Olsson, L. (2013). Long-term adaptation of Saccharomyces cerevisiae to the burden of recombinant insulin production. Biotechnology and Bioengineering. https://doi.org/10.1002/bit.24927

Simoes, R. D. M., Tripathi, S., \& Emmert-Streib, F. (2012). Organizational structure and the periphery of the gene regulatory network in B-cell lymphoma. BMC Systems Biology. https://doi.org/10.1186/1752-0509-6-38

Teixeira, M. C., Monteiro, P. T., Palma, M., Costa, C., Godinho, C. P., Pais, P., ... Sá-Correia, I. (2018). YEASTRACT: An upgraded database for the analysis of transcription regulatory networks in Saccharomyces cerevisiae. Nucleic Acids Research. https://doi.org/10.1093/nar/gkx842

Temple, M. D., Perrone, G. G., \& Dawes, I. W. (2005). Complex cellular responses to reactive oxygen species. Trends in Cell Biology. https://doi.org/10.1016/j.tcb.2005.04.003

Venables, W. N., \& Ripley, B. D. (2002). Modern Applied Statistics with S Fourth edition by. World. https://doi.org/10.2307/2685660

Vizcaíno, J. A., Côté, R. G., Csordas, A., Dianes, J. A., Fabregat, A., Foster, J. M., ... Hermjakob, H. (2013). The Proteomics Identifications (PRIDE) database and associated tools: Status in 2013. Nucleic Acids Research. https://doi.org/10.1093/nar/gks1262

Wenger, J. W., Piotrowski, J., Nagarajan, S., Chiotti, K., Sherlock, G., \& Rosenzweig, F. (2011). Hunger artists: Yeast adapted to carbon limitation show trade-offs under carbon sufficiency. PLoS Genetics. https://doi.org/10.1371/journal.pgen.1002202

Wright, N. R., Rønnest, N. P., \& Thykaer, J. (2016). Scale-down of continuous protein producing Saccharomyces cerevisiae cultivations using a two-compartment system. Biotechnology Progress. https://doi.org/10.1002/btpr.2184

Table 1: Average residual glucose concentration and glucose uptake rate in continuous phase for the recombinant strain and the wild-type strain cultivated in the single-compartment and two-compartment system. The average is an average of minimum 6 samples for 3 biological replicates.

\begin{tabular}{|c|c|c|c|c|c|c|}
\hline & \multicolumn{3}{|c|}{ Recombinant strain } & \multicolumn{3}{|c|}{ Wild-type strain } \\
\hline & \multirow{2}{*}{$\begin{array}{c}\begin{array}{c}\text { Single- } \\
\text { compartment } \\
\text { system }\end{array} \\
\\
\text { - } \\
\end{array}$} & \multicolumn{2}{|c|}{$\begin{array}{c}\text { Two- } \\
\text { compartment } \\
\text { system } \\
\end{array}$} & \multirow{2}{*}{$\begin{array}{c}\begin{array}{c}\text { Single- } \\
\text { compartment } \\
\text { system }\end{array} \\
\\
\text { - } \\
\end{array}$} & \multicolumn{2}{|c|}{$\begin{array}{c}\text { Two- } \\
\text { compartment } \\
\text { system } \\
\end{array}$} \\
\hline & & Tank 1 & $\begin{array}{c}\text { Tank } \\
2 \\
\end{array}$ & & $\begin{array}{c}\text { Tank } \\
1 \\
\end{array}$ & $\begin{array}{c}\text { Tank } \\
2 \\
\end{array}$ \\
\hline $\begin{array}{l}\text { Residual glucose } \\
\text { concentration } \\
{[\mathrm{mg} / \mathrm{L}]}\end{array}$ & $2 \pm 0.3$ & $5 \pm 1$ & $1 \pm 0.2$ & $8 \pm 1$ & $5 \pm 0.4$ & $1 \pm 0.2$ \\
\hline $\begin{array}{l}\text { Glucose uptake } \\
\text { rate } \\
{[\mathrm{mmol} / \mathrm{gDW} / \mathrm{h}]}\end{array}$ & 1.4 & 4.2 & 0.0 & 1.4 & 4.2 & 0.0 \\
\hline
\end{tabular}

Table 2: GO slim process terms which based on Fischer's exact test are enriched by the proteins in clusters of Figure 6 (q-values $<0.05)$. The GO process terms are collected from SGD Project (2019, July 17).

This article is protected by copyright. All rights reserved. 


\begin{tabular}{|c|c|c|}
\hline \multicolumn{3}{|l|}{ Recombinant strain } \\
\hline $\begin{array}{l}\text { Enriched GO terms in } \\
\begin{array}{l}\text { cluster } \\
\text { proteins) }\end{array}\end{array}$ & $\begin{array}{l}\text { Enriched GO terms in } \\
\begin{array}{l}\text { cluster } \\
\text { proteins) }\end{array}\end{array}$ & $\begin{array}{l}\text { Enriched GO terms in } \\
\begin{array}{l}\text { cluster } 4 \\
\text { proteins) }\end{array}\end{array}$ \\
\hline $\begin{array}{l}\text { Monocarboxylic acid metabolic process } \\
\text { Carbohydrate metabolic process } \\
\text { Generation of precursor metabolites and } \\
\text { energy } \\
\text { Cofactor metabolic process } \\
\text { Nucleobase containing small molecule } \\
\text { metabolic process } \\
\text { Response to oxidative stress } \\
\text { Cellular amino acid metabolic process } \\
\text { Lipid metabolic process } \\
\text { Cellular respiration }\end{array}$ & $\begin{array}{l}\text { Cytoplasmic translation } \\
\text { mRNA processing } \\
\text { Mitochondrial translation } \\
\text { rRNA processing } \\
\text { Ribosomal small subunit biogenesis } \\
\text { RNA splicing } \\
\text { Ribosome assembly } \\
\text { Transcription from RNA polymerase } \\
\text { III promoter } \\
\text { Ribosomal large subunit biogenesis }\end{array}$ & $\begin{array}{l}\text { Cytoskeleton organization } \\
\text { Ribosomal subunit export from } \\
\text { nucleus } \\
\text { Nuclear transport } \\
\text { Mitotic cell cycle } \\
\text { RNA modification } \\
\text { Nucleus organization } \\
\text { tRNA processing } \\
\text { Ribosomal large subunit biogenesis }\end{array}$ \\
\hline \multicolumn{3}{|l|}{ Wild-type strain } \\
\hline $\begin{array}{l}\text { Enriched GO terms in } \\
\begin{array}{l}\text { cluster } 4 \\
\text { proteins) }\end{array}\end{array}$ & $\begin{array}{l}\text { Enriched GO terms in } \\
\text { cluster } 1 \text { (increasing proteiı }\end{array}$ & \\
\hline $\begin{array}{l}\text { Monocarboxylic acid metabolic process } \\
\text { Carbohydrate metabolic process } \\
\text { Generation of precursor metabolites and } \\
\text { energy } \\
\text { Cofactor metabolic process } \\
\text { Nucleobase containing small molecule } \\
\text { metabolic process }\end{array}$ & $\begin{array}{l}\text { Cytoplasmic translation } \\
\text { mRNA processing } \\
\text { Mitochondrial translation } \\
\text { Cytoskeleton organization } \\
\text { Mitochondrion organization } \\
\text { Protein complex biogenesis } \\
\text { Transcription from RNA polymerase It }\end{array}$ & promoter \\
\hline
\end{tabular}

This article is protected by copyright. All rights reserved. 
Table 3: Transcription factors (TFs) significantly regulating more than $50 \%$ of the downregulated proteins (cluster 1, Figure 6) and $20 \%$ of the upregulated proteins (cluster 3+4, Figure 6) in the recombinant strain (Fischer's exact test, $q$ value $<0.05$ ). The transcription factors also found to regulate the upregulated (cluster 1, Figure 6) and downregulated (cluster 4, Figure 6) clusters in the wild-type strain are marked with bold. The description of TF function are based on SGD Project (2019, July 17).

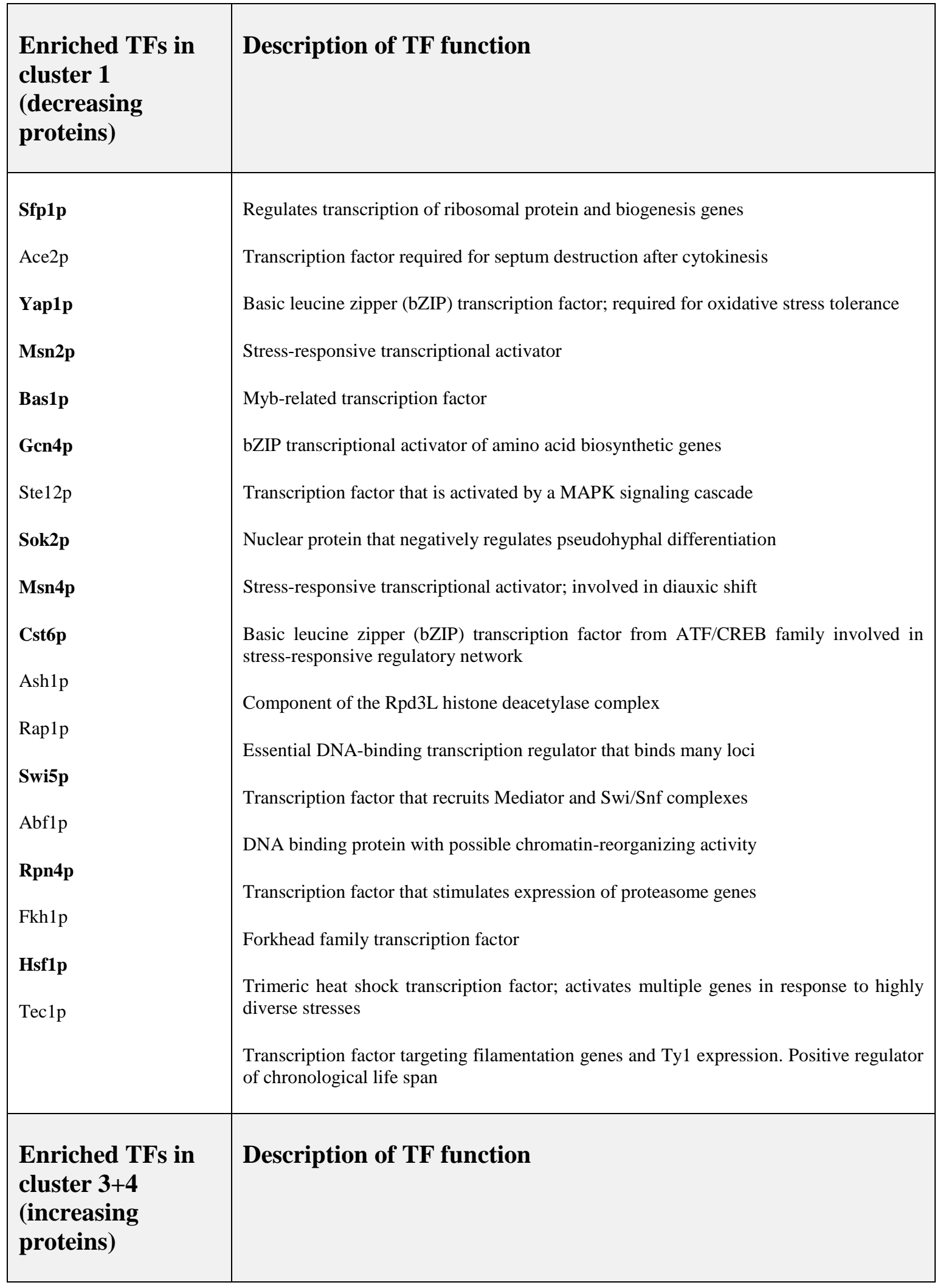

This article is protected by copyright. All rights reserved. 


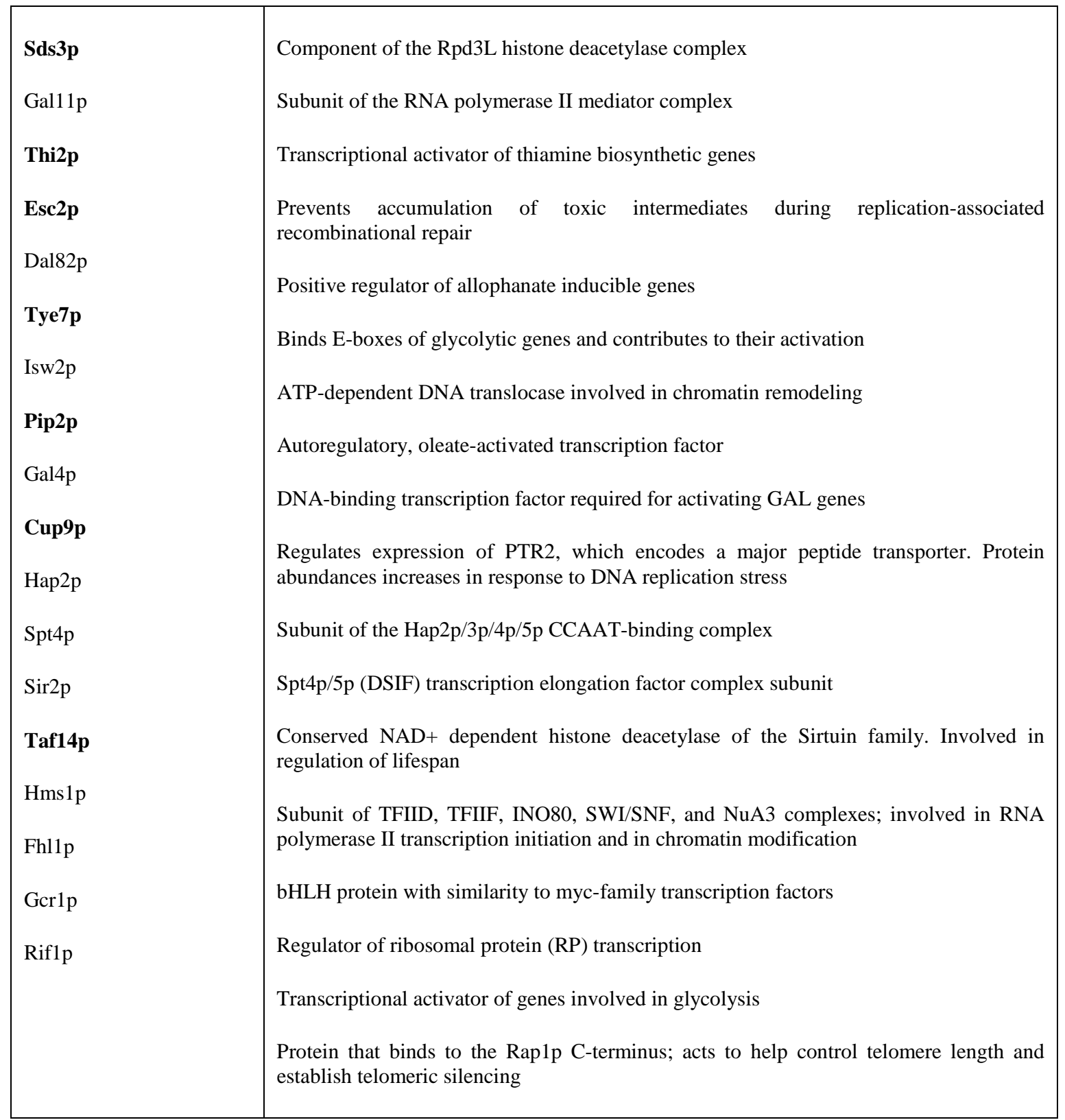

This article is protected by copyright. All rights reserved. 
Figure 1: Illustration of the cultivation systems applied in this study. Left: Single-compartment system with ideal mixing. Right: Two-compartment system simulating feast-famine conditions.

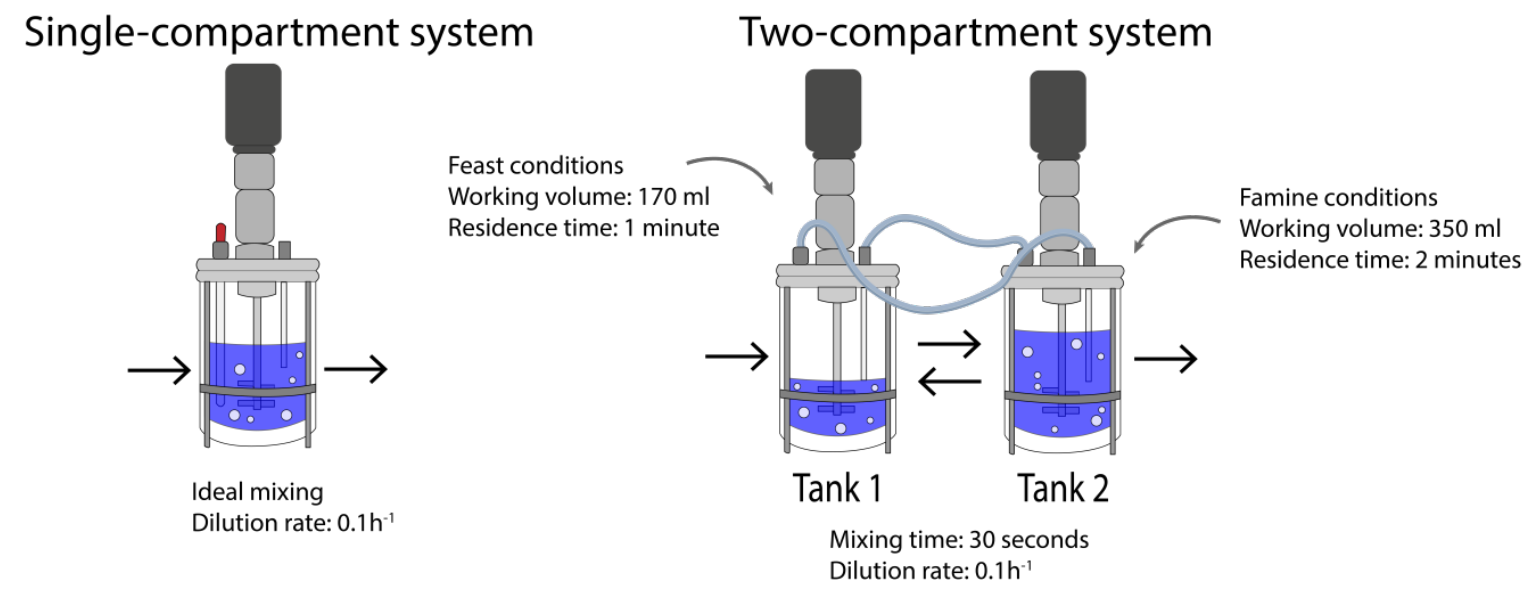

Figure 2: Extracellular insulin (A), biomass (B) and acetate concentration (C) in the cultivation broth as function of cultivation time for three biological replicates of the recombinant strain cultivated in the two-compartment system (filled squares) and in the $0.5 \mathrm{~L}$ single-compartment system (open circles).

A

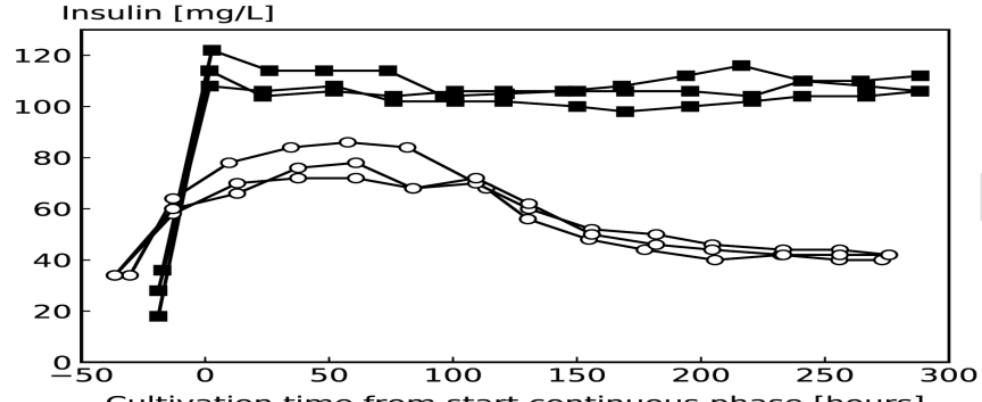

$\rightarrow-$ Two-compartment system
$\rightarrow-$ Single-compartment system

Cultivation time from start continuous phase [hours]

B

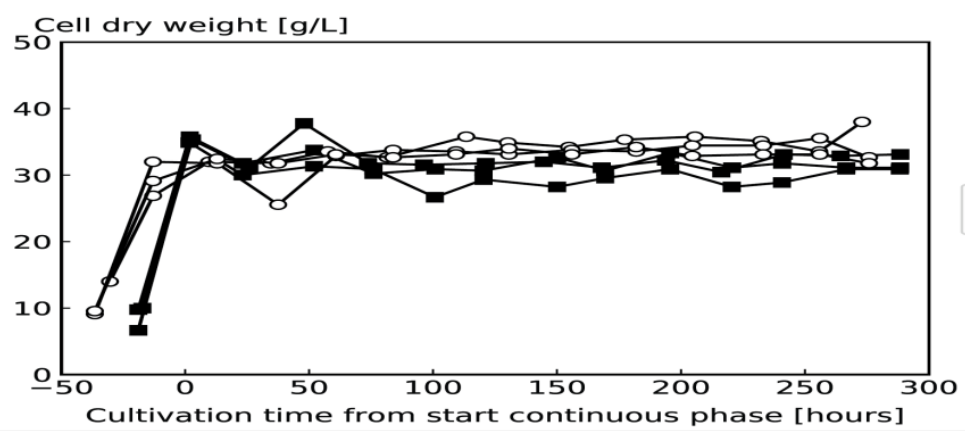

$\rightarrow-$ Two-compartment system Single-compartment system

C

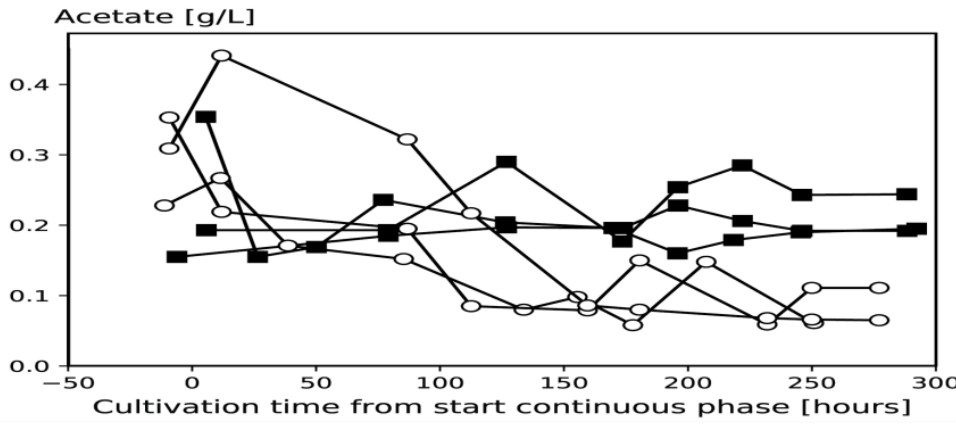

Two-compartment system Single-compartment system

This article is protected by copyright. All rights reserved. 
Figure 3: Carbon evolution rate (CER) as function of cultivation time for representative cultivations. A: Recombinant strain in $0.5 \mathrm{~L}$ single-compartment system, B: Recombinant strain in two-compartment system. The illustrated CER is measured from the off-gas of Tank 2, C: Wild-type strain in 0.5L single-compartment system, D: Wild-type strain in twocompartment system. The illustrated CER is measured from the off-gas of Tank 2.

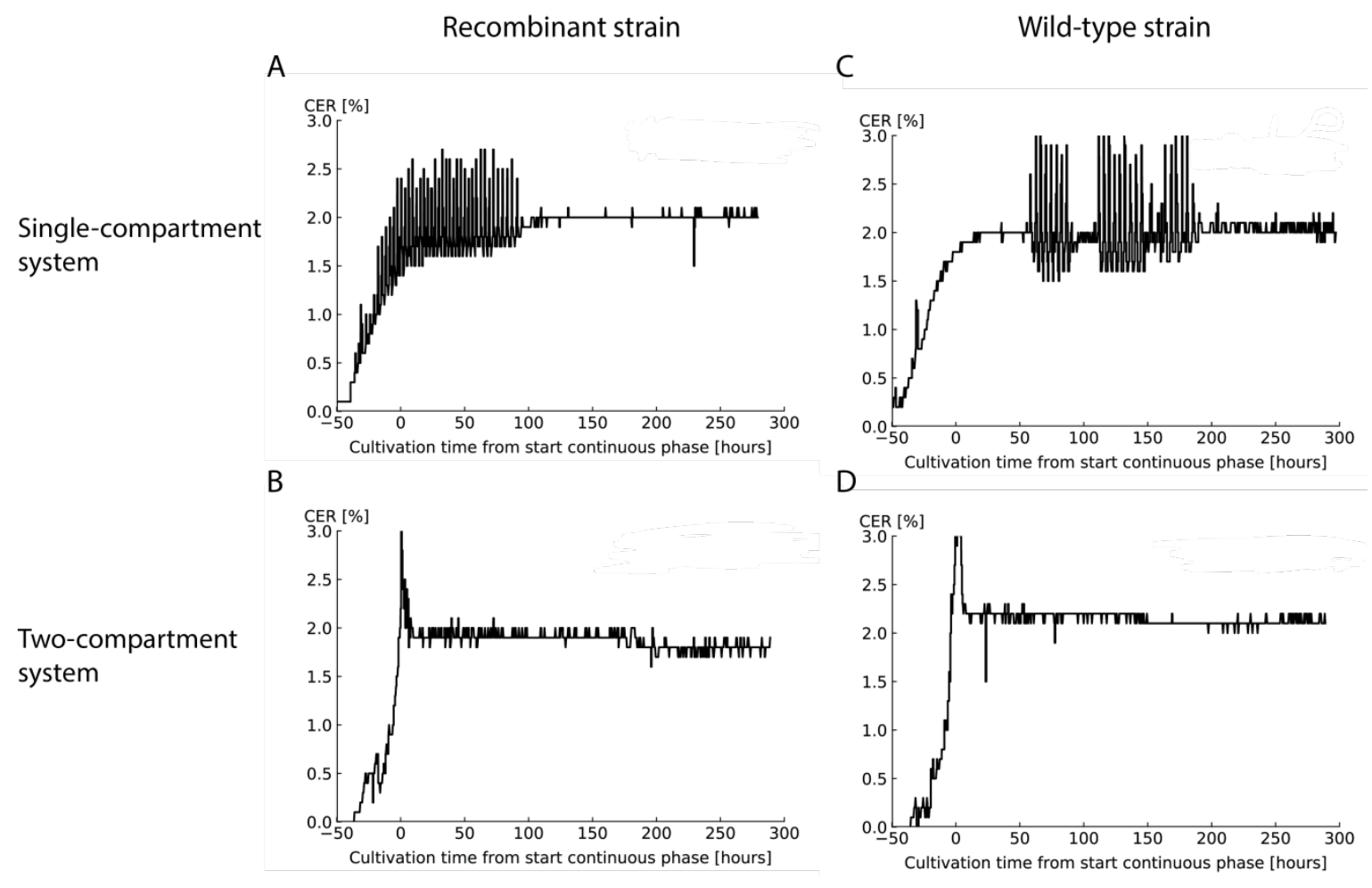

This article is protected by copyright. All rights reserved. 
Figure 4: Principle component analysis of proteomics samples for cultures with the recombinant strain in the $0.5 \mathrm{~L}$ and $2 \mathrm{~L}$ single-compartment system $(A)$, in the two-compartment system $(B)$, for cultures with the wild-type strain in the $0.5 \mathrm{~L}$ and $2 L$ single compartment system (C) and in the two-compartment system (D). Data represents samples from minimum three independent cultures with minimum five samples from each culture. For cultures in the two-compartment system, samples taken from both of Tank 1 and Tank 2 are shown. Numbers indicate the time point in hours from start continuous phase at which the sample is taken.

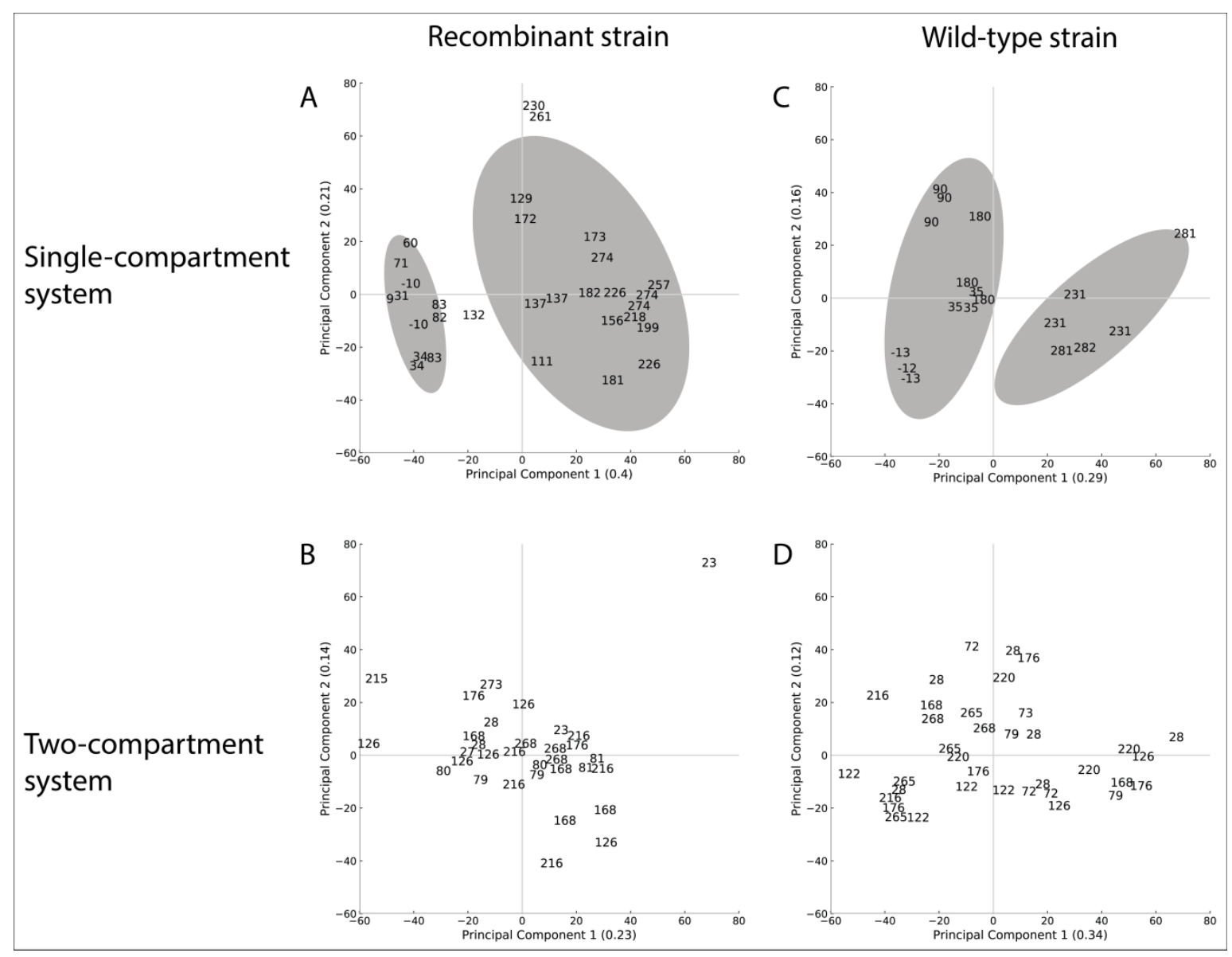

This article is protected by copyright. All rights reserved. 
Figure 5: Protein abundances of 3 glycolytic enzymes over time in the 0.5L single-compartment system (open circles) and in two-compartment system (filled squares) for three biological replicates of the recombinant strain and three biological replicates of the wild-type strain. The samples presented from the two-compartment system were taken from Tank 1. The abundances are scaled so the average across all the samples for a particular protein is 100.

\section{Recombinant strain}

Protein abundance

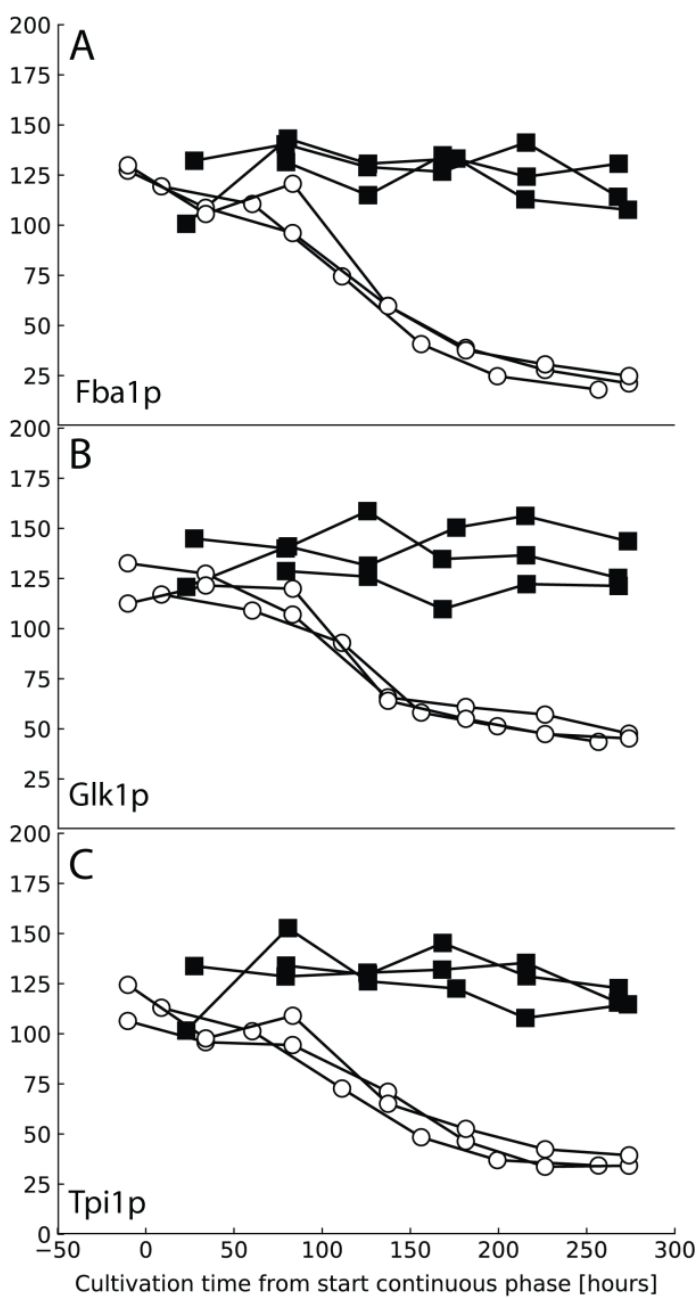

\section{Wild-type strain}

Protein abundance

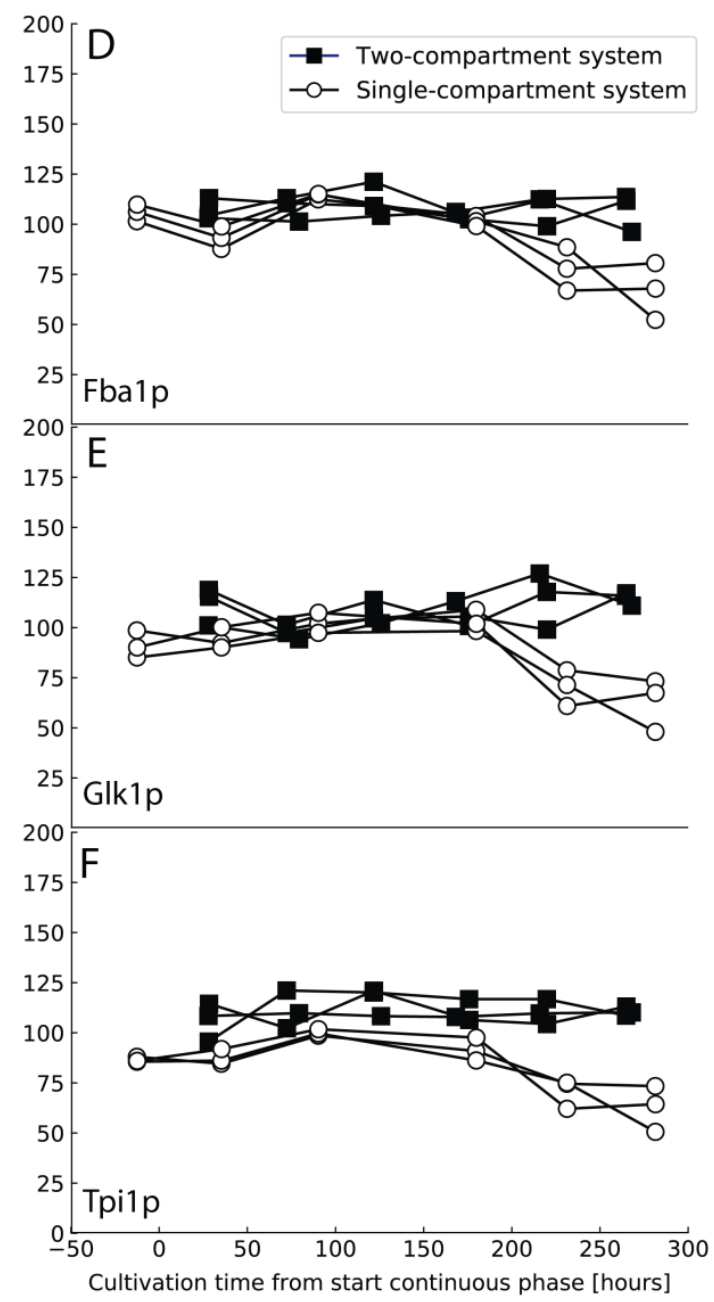

This article is protected by copyright. All rights reserved. 
Figure 6: Hierarchical clustering of intracellular proteins measured during the cultivation of the recombinant strain (A) and the wild-type strain $(B)$ in the both the $2 \mathrm{~L}$ and $0.5 \mathrm{~L}$ single-compartment system. The clustering is performed using the Ward method with Euclidean distance as distance measure. Y-axis show standardized protein abundances.
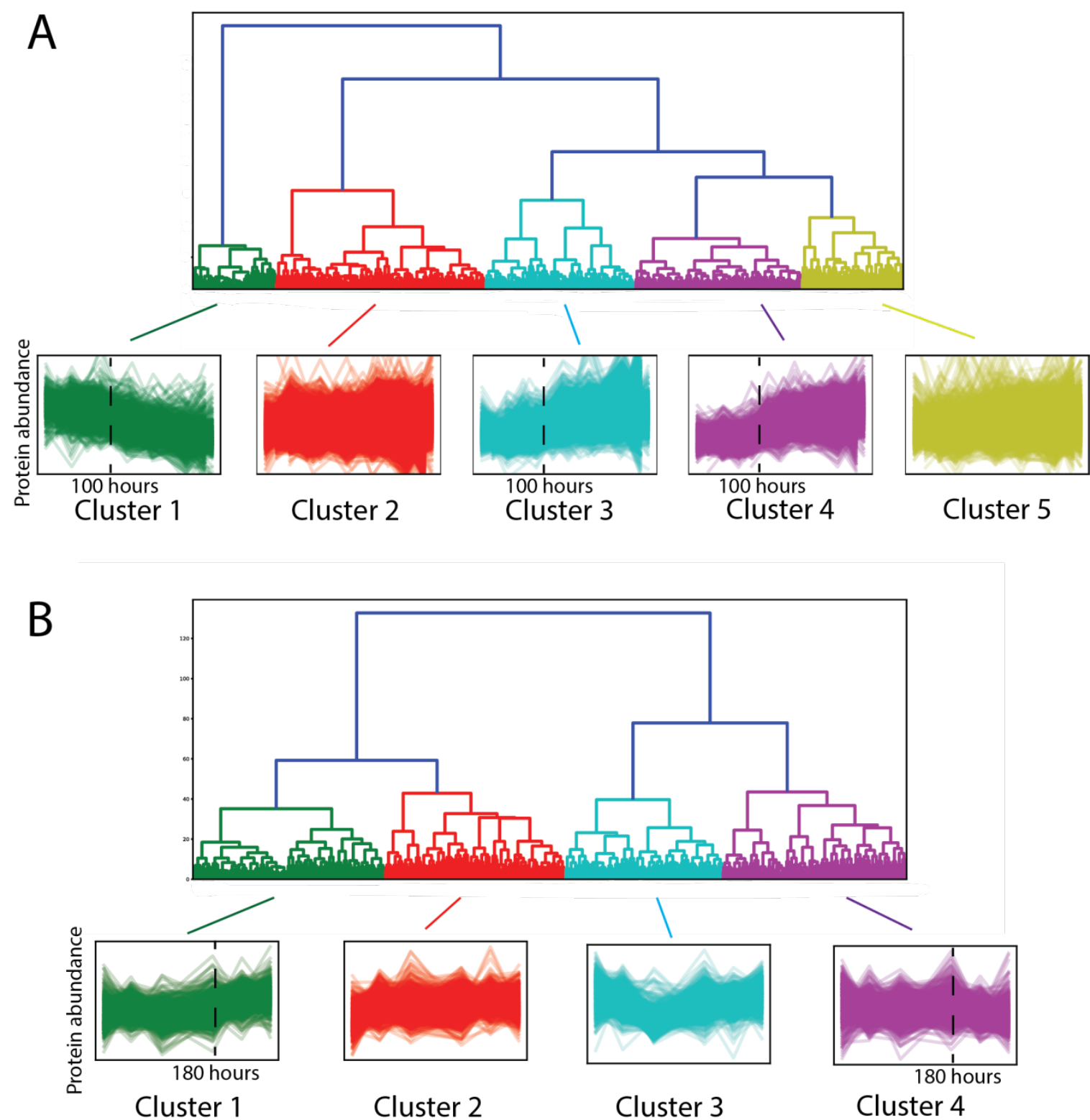

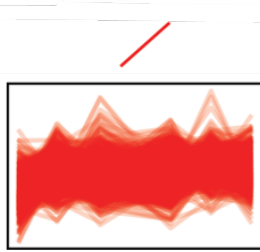

Cluster 2

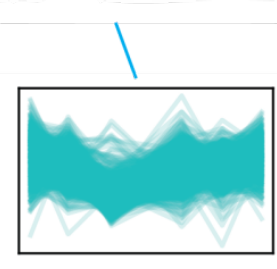

Cluster 3

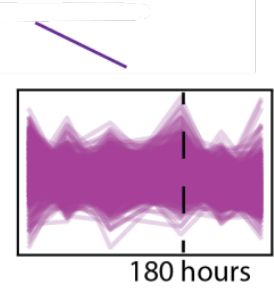

Cluster 4

This article is protected by copyright. All rights reserved. 
Figure 7: Suggested mechanisms involved in driving the proteomic changes in S. cerevisiae under prolonged well mixed conditions in single-compartment system, but at the same time resulting in a stable proteome under the influence of feastfamine conditions.

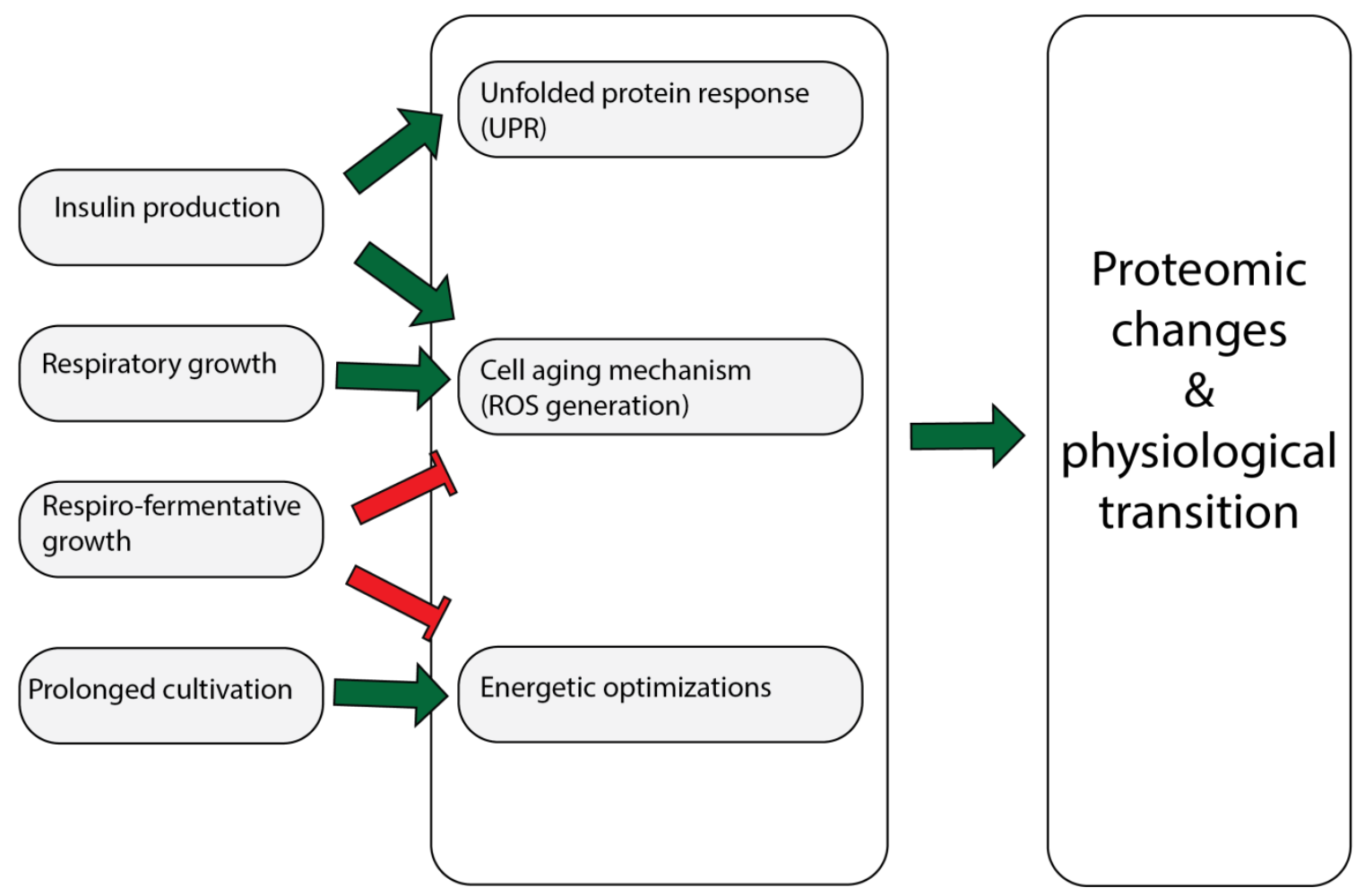

This article is protected by copyright. All rights reserved. 